\title{
The Knowledge Enhancement Process of Knowledge Workers
}

\author{
Carol G. McGowan \\ University of Wollongong Australia
}

\author{
Kate L.P. Reid \\ NSW Health Sydney Australia
}

Lee E.J. Styger

University of Wollongong Australia

\begin{abstract}
Using Constructivist Grounded Theory this research sought to explore the nature of knowledge workers and knowledge work itself. The interview findings reveal that knowledge workers have a set of processes they employ to remain connected and informed both personally and professionally in their domain area of expertise. They have learned to collect, curate, work with and share information to their best advantage. We have described this as knowledge workers knowledge enhancement process. A deeper understanding of this process has implications for organisations aiming to optimise the work of knowledge workers and for those teaching new knowledge workers for the future.
\end{abstract}

\section{INTRODUCTION}

It is widely acknowledgement in the literature that knowledge workers are a key resource in today's workplace (Yureva, Raffad, \& Tuomisto, 2013; Hammer, Leonard \& Davenport, 2004; Elliott \& Jacobson, 2002) and there has been considerable work undertaken in an attempt to understand their characteristics. However, we would contend that much of the research to date does not adequately take into account the human side of knowledge workers and therefore provides a limited understanding of how they operate in the world and the workplace. Typically, knowledge workers are analysed and reviewed using mechanistic measures which reflects historically how other fields such as medicine have sort to understand human beings. It is now increasingly recognised that while this lens has led to huge advances in our understanding it fails to capture the complexity of human beings and how they operate in the world. This paper presents research findings using a whole person centred approach to the characteristic of knowledge workers and their related ways of operating in the world to further their knowledge capabilities. This paper presents a small portion of a larger research project on the nature of knowledge workers and knowledge work. Initial findings from the early analysis of the interviews from this larger research activity will be presented. The research has used a Constructivist Grounded Theory (Charmaz, 2014) approach that was highly aligned to the research aim of developing a deep understanding of knowledge workers and the nature of knowledge work. It has brought to light previously undefined habits 
that knowledge workers utilise to enable them to maintain their capabilities and capacities in their domain area of expertise. This paper is focused on and describes their knowledge enhancement process.

\section{LITERATURE REVIEW}

Knowledge workers are believed to have been around since the beginning of time (Mladkova, 2011; Elliott \& Jacobsen, 2002). Elliot and Jacobsen (2002, p.69) state "the types of information professionals wax and wane with the information needs of the prevailing economic paradigm". The terms knowledge worker, information worker and information professional will be considered synonyms throughout this research with the more commonly used term 'knowledge worker' being employed. The term 'knowledge work' first appeared in the literature in the work of Peter Drucker in the 1950s and the term was then expanded by Fritz Machlup (1962) in his work "The Production and Distribution of Knowledge in the United States" (Dahooie, Afrazeh \& Hosseini, 2011; Pyöriä, 2005). These authors defined knowledge workers in relation to economic developments. Drucker in particular used the term to highlight the changing nature of work place responsibilities from a predominantly manually based to a more knowledge based workplace.

Nickols (1983) and Mladkova (2011) build on this concept further specifying the differences between manual work and knowledge work as being at the level of the work base unit. The work-base unit for manual work is materials based and for knowledge work it is information based (Nickols, 1983). Other distinctions of note are the visibility of the work done where in manual work visibility is high however in knowledge work it is low. The linkage to results is also made with manual work more direct and immediate whereas with knowledge work they are indirect and delayed. Nickols further describes a manual worker as working 'with' knowledge however a knowledge worker typically works 'with' and 'on' knowledge. Nickols is the only author that makes this specific distinction between working 'with' knowledge and working 'with' and 'on' knowledge. Scarbrough (1999) attempts to make a distinction between a knowledge worker and a professional by stating that professionals work 'from' knowledge and knowledge workers work 'with' knowledge. This raises questions as to the adequacy of this distinction and what value it adds. Trying to distinguish by professional category may only confuse the issue rather than providing further clarity on the nature of knowledge workers.

Changes in the definition have also occurred with the recognition of the increasing role of information and information technology within the workplace. In the 21 st century most, if not all workers, rely on knowledge to complete their workplace responsibilities so the term 'knowledge worker' does not provide the distinction it once did when it first offered by Drucker in the 1950s. Prior to 1860 less than 10\% of the workforce would be categorised as knowledge workers as most were working in a job shop where each piece of equipment was handmade (Elliott and Jacobson, 2002). However, by 1975 they had become the largest category in the workforce comprising more than $40 \%$ of the total workforce. Brinkley et. al., (2009) presents it as 33\% of the workforce have many knowledge tasks, $27 \%$ have some knowledge tasks and $40 \%$ have few knowledge tasks.

The literature suggests that we can recognise and define a knowledge worker in the $21^{\text {st }}$ century in the following ways:

- more likely to use their brains than their muscles (Mladkova, 2011) with an emphasis on intellectual capability rather than physical capacity

- capable of creating new insights and conveying these new ideas to others (Horwitz, Heng \& Quazi, 2003).

- needing to be able to cope with ambiguity, complexity and the uncertainty of dynamic situations (Hun Kim \& Benbasat, 2010; Vogt, 1995)

- possessing high levels of skill, education and abstract reasoning (Hammer, Leonard \& Davenport, 2004) 
- possessing the attributes of innovativeness, flexibility, being multiskilled, capable of adapting to change, creative, entrepreneurial, collaborative, reflexive, capable of solving problems and as having a commitment to life-long learning (Tennant, 2004)

- workers who have the ability to create new knowledge from existing knowledge (Bakotic, 2011)

- more likely to rely on "freewheeling informal networks" (Ehin, 2008, p.338)

- those who typically rely on voluntary behaviour not conformity to a set of rules (Moss Kanter, 2000)

- people "who know more about their job than anyone else in the organization" (Acsente, 2010, p.280)

- "Those who need to use a high level of knowledge and information in their day to day activities to complete their workplace tasks" (Jashapara, 2011, p.342)

- possessing certain habits such as: having an open worldview, seek to find a hidden interest, stay focussed when things get tough, are willing to voice concerns, keep their knowledge current, need to manage increasing stimuli in the workplace, may resent technological advances, may inappropriately prioritise tasks based on urgency rather than importance, like to play with gadgets (Yureva, Raffad, \& Tuomisto, 2013)

The difficulty with these descriptors is they define intangible and complex phenomena with broad non-specific terms and attributes which provides limited insight into the nature and processes involved in knowledge work and in turn knowledge workers. The other problem is that these broad terms do not clearly differentiate knowledge workers from other worker groups eg: knowledge workers have the capacity to create new insights and convey new ideas as suggested by Horwitz, Heng \& Quazi, (2003) could be said of groups called 'innovators', 'researchers' or 'entrepreneurs'.

One way authors have attempted to be more specific on the work on knowledge workers is that they have described the specific tasks or actions they do in a similar fashion to the way you might describe a production line in a factory operation. In the work of Brinkley et al (2009) they used activities such as compiling data, judging the speed of moving objects, stocking shelves with products as aspects for analysis. In the research undertaken by Rinehardt et. al. (2011) they focussed their analysis on the use of a computer using sensors to assess key strokes on a PC with this being a task execution analysis which excluded the value add the individual brings ie: how do they know the keystrokes to use. The specific tasks used for analysis purposes were assessing job applications and creating a presentation which are not activities uniquely undertaken by knowledge workers and do not necessarily require specialised capabilities and capacities to enable completion. This type of analysis could be considered better suited to manufacturing than to the endeavours of human beings.

A number of authors have taken a command-control approach to studies of knowledge workers with the purpose of improving productivity. This could be understood as organisations and/or societies expressed desire to control knowledge workers. This is very clearly demonstrated in Yureva, Raffad, \& Tuomisto (2013) who for example describe knowledge worker as resenting technological advances, inappropriately prioritise tasks based on urgency rather than importance, like to play with gadgets. Some might term these descriptions as disparaging or derogatory with the aim of attempting to address or overcome knowledge workers to the advantage of the organisation with little or inadequate consideration of the individual and/or their situation. This approach is insufficient and inappropriate for the $21^{\text {st }}$ century workplace.

Still other authors suggest that knowledge works are distinguished by the roles they occupy within an organisation suggesting that all knowledge workers are executives (Drucker, 1999) or that they are more likely to utilise information technology to complete their workplace responsibilities (Griffin, 2002 cited in Bakotic, 2011). Other authors take what could be seen as the more obvious route to define a knowledge worker by using professional categories such as "doctors, lawyers, researchers, academics, architects, engineers and management consultants" and golf caddie (Frick, 2011; Levinson, 2007; Vogt 1995, p.30; 
Rouse, n.d.). Spira (2008) in his article adopts a different approach to defining a knowledge worker by stating what they are not ie: they are not factory workers, labourers or field or farm workers. While this approach does provide some clarity, it has limited usefulness in trying to understand the nature of knowledge work and knowledge workers.

While some authors acknowledge that there is no one easy acceptable definition of knowledge worker and the original distinction and description is no longer valid, in response some authors attempt to provide distinctions within the category of knowledge worker including such terms as: creators of knowledge work, portable knowledge work, specialty knowledge work (Ramirez \& Nembhard, 2004), elite knowledge workers, and high-end knowledge workers (Acsente, 2010), gifted knowledge worker (Tyman \& Stumpf, 2003). Davenport, Thomas \& Cantrell (2002) support this viewpoint when they state putting all knowledge workers in one group is erroneous because they can vary based on a number of different factors such as their organisational status and degree of influence, their specific work environment and finally the specific work practices and procedures they follow. However, we would argue that the need to make such distinctions highlight the need for a better understanding of knowledge workers in the $21 \mathrm{st}$ century workplace.

It is a recognition of the changes that exist in the 21 st century workplace being noticeably different from what took place in the 20th century especially the late 20th century workplace that has influenced the desire to understand knowledge workers in a more comprehensive way. As stated previously by 1975 knowledge workers had become the largest category in the workforce comprising more than $40 \%$ of the total workforce (Elliott and Jacobson, 2002) or as explained by Brinkley et al (2009), 33\% of the workforce have many knowledge tasks, $27 \%$ have some knowledge tasks and $40 \%$ have few knowledge tasks. Whichever way you look at it knowledge work is now the predominant category of workers in the workforce so having one term to describe all of them could be considered problematic. In contrast to Callahan's (2007) somewhat controversial view that 'knowledge worker' is a meaningless term which no longer has relevance, while we acknowledge the difficulty in the task the prevalence of knowledge workers in our 21 st century workplace suggests that it is endeavour worth undertaking and while there are obvious differences within this broad group they also have a set of common characteristics which provide a useful and meaningful reference point.

On close analysis, it can be said much of the research on knowledge workers that appears in the literature is rhetorical. It talks about them not too them and in ways that seek to enhance production (Davenport, Drucker etc.) as you would machinery. It does not sufficiently take into account who they are as human beings and what influences and impacts who they are and what they do in their roles as knowledge workers. For those who have undertaken empirical studies related to knowledge workers it could be argued that in some cases inadequate or inappropriate sample groups have been chosen. One example of this is the work done by Reinhardt et. al. (2011) where they used researchers with Masters qualifications or Doctorates and doctoral students to examine what they do as knowledge workers and they used a computer programme analysing key strokes to determine what they do as knowledge workers. This confirms what has been found in the literature that an execution centric approach is often used when seeking to understand knowledge workers and what they do. Again, this neglects who they are. In the work of Mladkova (2011) related to the management of knowledge workers she used policemen, firemen and soldiers within the Czech Republic as the participants of her research. Both the work of Reinhardt et al. (2011) and Mladkova (2011) they have chosen highly specialised and somewhat insular participants groups to attempt to better understand knowledge workers without clearly articulating what makes these groups appropriate examples of knowledge workers for the purposes of better understanding knowledge workers.

There was a comprehensive study on knowledge workers undertaken by Brinkley et al 2009 on understanding knowledge workers it again was mechanistic and execution centric and the mechanisms used to assess knowledge work undertaken by knowledge workers appeared to be based on routine or easily conceptualised tasks eg: data process and analysis tasks, administrative tasks, people management tasks rather than the more complex tasks often assigned to and undertaken by knowledge workers. In the Brinkley et. al. 2009 study only one group of tasks called "perceptual and precision tasks" (p.22) were 
included in a group of 10 group categories. This group of tasks contained 11 activities out of a total activity count of 126 for all categories.

From this analysis, it highlighted the fact that there has been very little investigation on the routines and habits of knowledge workers. What there has been is an emphasis on the quantity of work produced or type of work undertaken rather than on the actions they take in order to be able to complete the workplace tasks requested of them.

\section{THE METHODOLOGY AND MODEL}

In response to the initial examination of the literature the research approach was to undertake the investigation with an open mind and a high degree of curiosity as to who are knowledge workers in the 21 st century. What might we find out about knowledge workers to build on from what we already know? A qualitative research approach has been adopted where data was obtained through conducting in-depth semi-structured interviews using a Constructivist Grounded Theory approach (Charmaz, 2014). Grounded Theory as a method was first described by Glaser and Strauss in their landmark book called Understanding Grounded Theory in 1967 and has been widely acknowledged by other Grounded Theory researchers since that time including well known researchers such as Easterby-Smith, Thorpe \& Jackson, 2012, Birk \& Mills, 2011, Denzin \& Lincoln, 2011, Eriksson \& Kovaleinen, 2008.

Constructivist Grounded Theory has evolved as the use of the Grounded Theory method has developed and become a widely accepted and valuable research methodology. Taking a qualitative approach to this analysis was necessary because it was important that the participants stories could emerge as part of the discussion and there was no attempt to elicit specific responses from participants.

It was not obvious initially who should be interviewed as knowledge workers do not have an easily definable boundary and the goal was to encourage a broad analysis. In light of this some broad generic selection criteria were developed based on insights gained from undertaking the sensitising literature review. Key aspects identified for developing a valid set of selection criteria were who were knowledge workers, developing expertise and mastery in a domain area of expertise, attitudes towards learning and length of experience in their domain area of expertise. Consideration of these factors led to the development of 11 selection criteria an approach also used by Law \& Du-Babcock (2017) when determining participants for their research activity. It was decided that if potential participants met at least 5 of the 11 criteria that would make them suitable candidates for interview. This decision has been supported by endorsement through the Ethics Committee of the affiliated university. The selection criteria used for this research were:

- Do you possess at least 15 years experience in your domain area of expertise?

- Are you associated with \&/or recognised by a community of practice?

- Are you associated with \&/or recognised by a professional association?

- Have you attained the highest credential level available through your professional association eg: Master, Expert, Charted, Fellow etc.?

- Do people seek your opinion \&/or guidance within your domain area of expertise?

- Have you been published by a recognised and reputable 3rd party not just self-promotion?

- You have made a tangible contribution to your industry

- You are an educator or mentor in your domain area of expertise

- You have received external awards for your contribution to industry

- You possess and have been identified as possessing a highly specialised (unique) skill set

- You demonstrate a recognised commitment to on-going development of professional expertise and continuous education

A purposive sample approach was used and initially sourced through relevant professional networks after appropriate ethics approval had been obtained. Interviews ranging in duration from 40 - 90 minutes were conducted. Each interview was recorded, transcribed and then coded using the approach suggested 
by Saldana (2013) in his book entitled the Coding Manual for Qualitative Researchers. The approach outlined by Saldana involves a multi cycle approach to coding allowing themes to emerge from the coding process which through varying degrees of abstraction become categories which help lead to the development of theories when a Grounded Theory Approach is used. The findings of this research have been extracted as a result of this coding process.

\section{THE FINDINGS}

Themes and concepts emerged naturally during the analysis process with one of the interesting insights being that each subsequent interview built on the themes of the previous interview by providing more depth and understanding of the concepts being raised. The participants came from a wide range of domain areas of expertise and not necessarily occupations or pursuits that are commonly referenced in the research as be synonymous with knowledge workers eg: bespoke instrument maker, physiotherapist, technical specialist in corrosion of oil and gas pipes. This was a deliberate choice to aid in achieving objectivity and minimising any potential form of bias from an occupational background perspective, found to be one of the weaknesses in the extant literature. Defining a knowledge worker simply by their job role was revealed to be inadequate.

While there are a number of themes emerging from the research this paper will focus on three related factors that have been entitled the 'Knowledge Workers Knowledge Enhancement Process'. This umbrella theme has a number of sub themes contained within it and each will be discussed in turn. See Figure 1 below for an overview of the knowledge enhancement process.

\section{FIGURE 1 KNOWLEDGE WORKERS KNOWLEDGE ENHANCEMENT PROCESS}

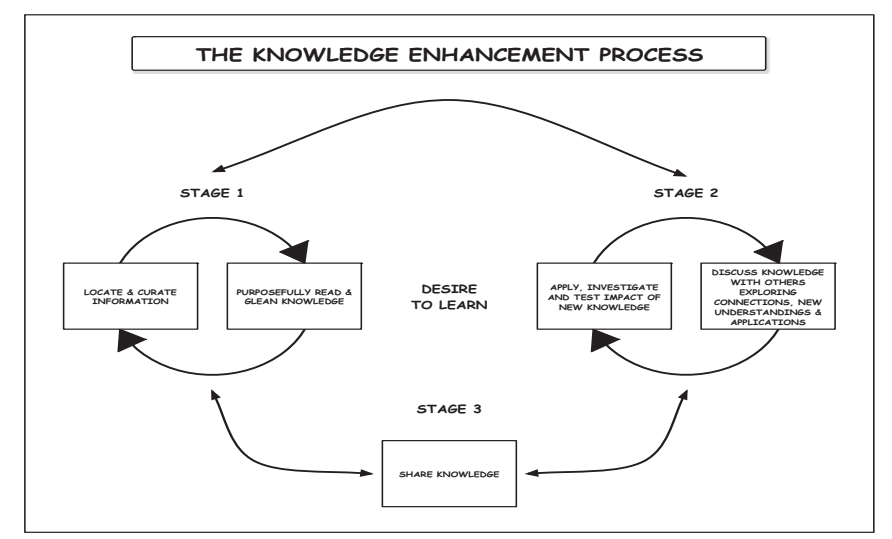

The first stage of the Knowledge Enhancement Process to emerge from the interviews was that knowledge workers are purposeful readers. This is a previous undefined characteristic of the practice of knowledge work and the knowledge enhancement process. In each of the instances analysed the interviewees described how they actively and deliberately sought out material to read and that there was a purpose and intent behind what they read. For Interviewee Number 2 he described it as a 'fascination' with his subject and a desire to continue to learn even though he possessed nearly 40 years experience in his chosen field. He felt this was just a natural thing to do. Interviewees Number $3 \& 4$ outlined how they had a detailed plan of what they read and when to ensure they maintained connection to their industry and domain area of expertise. When considering what the participants said and their demeanour when providing their responses, the following insights were gained:

- There was an intrinsic drive to undertake this reading almost as if they could not control it

- They believed that this was essential it was not a choice but a must 
- They were highly motivated and passionate about the activity and experienced it as a very positive undertaking

- They were pleased someone wanted to listen to their story about what they did

A key aspect that came from their discussion of their purposeful reading approach is that they have developed skills in being able to curate the information they wish to access. This means they have the ability to bring together information and sift through it to find what is most relevant to their need and purpose at any given time. In the digital age curation has been defined as the process of searching on-line information sources and repositories and then collecting and interpreting information to enhance and develop a current area of knowledge and understanding (Webb et. al., 2013). This is something the participants in this research activity appeared to be capable of doing well. This ability is a skill that contributes to the knowledge enhancement process employed by knowledge workers.

The second stage of the knowledge enhancement process that emerged from the research related to knowledge workers is that simply acquiring information was not enough. They then went on to actively seek ways to apply what they had learnt. This occurred in one of two ways. Either they tried to apply it within workplace contexts (even though that might not have been the driver to acquire the information in the first place) or they sought to discuss it with others within their community of practice where they are able to find others who share an interest or are able to 'speak the language' to help facilitate their learning process (Baker \& Beames, 2016; Wenger, 2011). Both of these approaches were employed to embed the learning in meaningful ways. In these instances, it is a clear demonstration that knowledge workers are heutagogical learners (Richardson, McGowan \& Styger, 2017) in that they are "highly autonomous and self-determined" (Blaschke, 2012, p.56) in their approach to learning. This finding is supported by comments by Rogers 1951 cited in Halsall, Powell and Snowden, (2016) that learning is a process that is innate, hence it is within the individual and they control what they want to learn whereby they create their own unique personal space. While they can seek out mentors or teachers they have a well-developed capacity to teach themselves.

The third stage of the knowledge enhancement process identified that completes the process of knowledge workers is that after they have actively sought out information, applied, discussed and embed what they have learnt they then seek to share their newly acquired knowledge and understanding with others. Their express purpose in this process is the belief and intent that others will benefit from the new insights and information they have acquired. One explanation of this is phenomena was outlined by the developmental psychologist Eric Erickson who said that our inherent nature drives us to want to teach others, hence we are a teaching species (Dixon, 2009). This is evidence by the fact that much of our initial history was passed on by older generations teaching younger generations. Ironically this is a role that knowledge workers have played throughout time. It could be said that all that has changed is the methods and mechanisms used to convey the knowledge from one to another.

\section{SUMMARY AND CONCLUSIONS}

When the findings from this research are compared with what is found in the existing literature there is a clear difference in emphasis and focus. The extant literature for the most part has had a mechanical and arms-length analysis whereas this research provides some insight into how knowledge workers are as individuals and some of the processes or habits they employ to maintain their capabilities and competencies in their domain area of expertise. They are willing to take on responsibility for their own learning and are not solely reliant on learning opportunities that may be provided to them through their place of employment. However, it is believed understanding the actions, intentions and processes identified through this research will provide insight and benefits to organisations when seeking to establish and maintain environments conducive to harnessing the best from the knowledge workers that they employ.

The implications, based on the research findings is that organisations can take these factors into account when seeking to engage, retain and develop knowledge workers. From an organisational 
perspective, this means that it would be beneficial to allow knowledge workers time to undertake purposeful reading as part of their everyday work practices and processes. Organisations would then be in a position to optimise and take advantage of the fact that knowledge workers typically then seek to apply their learning and share with others, all parts of their knowledge enhancement process. Organisations could use the process to increase productivity by honouring and directing the process to the benefit of all affected. This seems somewhat incongruous when you consider that organisations are looking to develop and enhance competitive advantage and they are overlooking or are not aware a significant area in which they benefit their organisations and those that work within their organisations. There is also implication for institutions educating knowledge workers and the capacity to actively teach the knowledge enhancement process.

\section{REFERENCES}

Ascente, D. (2010). Literature review: a representation of how future knowledge worker is shaping the twenty-first century workplace. On The Horizon, 18, (3), 279-287.

Baker, A. \& Beames, S. (2016). Good CoP: what makes a community of practice successful?. Journal of Learning Design, 9, (1), 72-79.

Bakotic, D. (2011). Knowledge workers in Croatian companies. The Business Review, Cambridge, $17,(2), 97-102$.

Birks, M. \& Mills, J. (2011). Grounded theory: A practical guide. London: Sage Publications.

Blaschke, L.M. (2012). Heutagogy and lifelong learning: a review of heutagogical practice and selfdetermined learning. The International Review of Research in Open and Distance Learning, $13,(1), 56-71$.

Brinkley, I., Fauth, R., Mahdon, M. \& Theodoropoulou, S. (2009). Knowledge workers and knowledge work - A knowledge economy programme report. The Work Foundation London England. Retrieved from https://www.researchgate.net/publication/263511078_Knowledge_Workers_and_Knowledge_Wo rk_A_Knowledge_Economy_Programme_Report

Callahan, S. (2007). Our need for the knowledge worker is over. Anecdote, November 3, 2007. Retrieved from http://www.anecdote.com/2007/11/our-need-for-knowledge-worker-over/

Charmaz, K. (2014), Constructing grounded theory, $2^{\text {nd }}$ Edition. London: Sage Publications.

Dahooie, J.H., Afrazeh, A. \& Hosseini S.M.M. (2011). An activity-based framework for quantification of knowledge work. The Journal of Knowledge Management. 15, (3), 422-444.

Davenport, T., Thomas, R.J. \& Cantrell S. (2002). The mysterious art and science of knowledge-worker performance. MIT Sloan Management Review, 44, (1), 23-30.

Denzin, N.K. \& Lincoln, Y.S. (Eds.). (2011). The SAGE handbook of qualitative research, $4^{\text {th }}$ Edition. Thousand Oaks, California: Sage Publications.

Dixon, N. (2009). The incentive question or why people share knowledge. Retrieved from http://www.nancydixonblog.com/2009/03/the-incentive-question-or-why-people-shareknowledge.html

Drucker, P. (1999). Knowledge-worker productivity: the biggest challenge. California Management Review, 41, (2), 79-94.

Easterby-Smith, M., Thorpe, R. \& Jackson, P. (2012). Management research, $4^{\text {th }}$ Edition. London: Sage Publications.

Ehin, C. (2008). Un-managing knowledge workers. Journal of Intellectual Capital, 9, (3), 337-350.

Elliott, R.K. \& Jacobson, P.D. (2002). The evolution of the knowledge professional. Accounting Horizons, 16, (1), 69-80.

Eriksson, P. \& Kovalainen, A. (2008). Qualitative methods for business research. London: Sage Publications.

Frick, D.E. (2011). Motivating the knowledge worker. A publication of the Defense Acquisition University, retrieved from 
https://www.dau.mil/library/arj/_layouts/15/WopiFrame.aspx?sourcedoc=/library/arj/ARJ/arj60/F rick ARJ60.pdf\&action $=$ default

Halsall, J.P., Powell, J.L. \& Snowden M. (2016). Determined learning approach: implications of heutagogy society based learning. Cogent Social Sciences, 2, 1-11.

Hammer, M., Leonard, D. \& Davenport T. (2004). Why don't we know more about knowledge?. MIT Sloan Management Review, 45, (4), 14-18.

Horwitz, F.M., Heng, C.T. \& Quazi H.A. (2003). Finders, keepers?. Attracting, motivating and retaining knowledge workers. Human Resources Management Journal, 13, (4), 23-44.

Hun Kim, T. \& Benbasat, I. (2012). Effectiveness of knowledge seeking behaviours embedded in social networks: a perspective of individuals in the workplace. $45^{\text {th }}$ Hawaii International Conference on System Sciences, Maui, Hawaii USA, January 4-7, 2012.

Jashapara, A. (2011). Knowledge management: An integrated approach. Harlow, Essex: Prentice-Hall.

Law K.K \& Du-Babcock B. (2017). How hierarchical positions affect employees' knowledge sharing behaviours: An exploratory study. Journal of Organizational Psychology, 17, (5), 129-138.

Levinson, M. (2007). Knowledge management definitions and solutions. Tutorial, CIO March 2007. Retrieved from www.cio.com/article/2439279/enterprise-software/knowledge-managementdefinition-and-solutions.html

Mladkova, L. (2011). Knowledge management for knowledge workers. The electronic journal of knowledge management. 9, (3) pp.248-258.

Moss Kanter, R. (2000). Knowledge workers. Executive Excellence, January 2000, 15-16.

Nickols, F.W. (1983). Half a needs assessment - what is in the world of work and working. Performance and Instruction Journal, October 1983, 24-27.

Pyöriä, P. (2005). The concept of knowledge work revisited. Journal of Knowledge Management, 9, (3), 116-127.

Ramirez, Y.M. \& Nembhard, D.A. (2004). Measuring knowledge worker productivity: a taxonomy. Journal of Intellectual Capital, 5, (4), 602-628.

Richardson, L.P., McGowan, C.G. \& Styger L.E.J. (2017). Heutagogy - An updated approach to Masters Education. In: Proceedings of the 20th Excellence in Services International Conference (formally Toulon-Verona Conference), Verona, Italy, 7-8 September 2017.

Rinehardt, W., Schmidt, B., Sloep, P. \& Drachsler, H. (2011). Knowledge worker roles and actions results of two empirical studies. Knowledge and Process Management, 18, (3), 150-174.

Rouse, M. (n.d.). Knowledge Worker. Retrieved from http://searchcrm.techtarget.com/definition/knowledge-worker

Saldana, J. (2013). The coding manual for qualitative researchers, $2^{\text {nd }}$ Edition. London: Sage Publications.

Scarbrough, H. (1999). Knowledge as work: conflicts in the management of knowledge workers. Technology Analysis \& Strategic Management, 11, (1), 5-16.

Spira, J. (2008). Knowledge worker: do you relate?. KM World, 17, (2), 1 \& 26.

Tennant, M. (2004). Doctoring the knowledge worker. Studies in Continuing Education, 26, (3), 431-441.

Tyman, W.G. \& Stumpf, S.A. (2003). Social capital in the success of knowledge workers. Career Development International, 8, (1), 12-20.

Vogt, E.E. (1995). The nature of work in 2010. Telecommunications, 29, (9), 21-24 and 28-34.

Webb, A.M., Linder, R., Kerne, A., Lupfer, N., Qu, Y., Poffenberger, B. \& Revia, C. (2013). Promoting reflection and interpretation in education: curating rich bookmarks as information composition. Retrieved from http://ecologylab.cse.tamu.edu/research/publications/curatingRichBookmarks.pdf

Wenger, E. (2011). Communities of practice: a brief introduction. Retrieved from https://scholarsbank.uoregon.edu/xmlui/handle/1794/11736

Yureva, A., Raffad, A. \& Tuomisto, A. (2013). Knowledge worker habits - identification, description and valuation of the diverse habits of knowledge workers'. Executive Summary, Work Infomatics University of Turku. Retrieved from http://mb.cision.com/Public/145/9513793/890bb15ca906ea44.pdf 